\title{
Experimental Study of Near-Wall Liquid Film Outflow with Co-Current Gas Flow from Nozzle into Vacuum. 1. Interaction Inside Nozzle
}

\author{
Yuri N. Vyazov, Victor G. Prikhodko, Igor V. Yarygin, Vyacheslav N. Yarygin
}

Kutateladze Institute of Thermophysics SB RAS, Novosibirsk, 630090, Russia

yarygin@itp.nsc.ru

\begin{abstract}
Interaction of co-current gas flow with near-wall liquid film inside a nozzle (cylindrical channel) under ejection into vacuum is studied experimentally. Local parameters of near-wall films of ethanol, water and their mixtures under interaction with co-current air flow are measured with the help of capacity-type probes. It is shown that under conditions of experiments carried out co-current flow exert strong dynamic impact on near-wall liquid film, leading to intensive wave formation, detachment of droplet and their dispersal by co-current flow. It is found that the amount of liquid entrained from boundary surface can reach over $50 \%$ from the initial flow rate of liquid. Flow structure of gas-droplet jet arising under ejection into vacuum is visualized with the help of laser illumination. Appearance of droplets backflows (at angles over $90^{\circ}$ with respect to nozzle axis) is shown. Temperature of the film formed on the nozzle external surface is measured. It is shown that the film of liquid is cooled down to the temperature at which its saturated vapor pressure becomes equal to pressure in vacuum chamber.
\end{abstract}

Keywords: nozzle, vacuum, near-wall film, water-ethanol mixture, interface phenomena 


\title{
Экспериментальное исследование истечения пристенных пленок жидкости со спутным газовым потоком из сопла в вакуум. 1. Взаимодействие внутри сопла
}

\author{
Ю.Н. Вязов, В.Г. Приходько, И.В. Ярыгин, В.Н. Ярыгин \\ ФГБУН Институт теплофизики им. С.С. Кутателазде СО РАН, \\ Россия, Новосибирск, 630090, просп. Академика Лаврентьева, д.1 \\ yarygin@itp.nsc.ru
}

\begin{abstract}
Аннотация
Экспериментально исследуется взаимодействие спутного газового потока с пристенной пленкой жидкости внутри сопла (цилиндрического канала) с последующим истечением в вакуум. С использованием зондов емкостного типа измерены локальные параметры пристенных пленок этанола, воды и их смесей при взаимодействии со спутным потоком воздуха. Показано, что в условиях проведенных экспериментов спутный поток оказывает сильное динамическое воздействие на пристенную пленку жидкости, приводя к интенсивному волнообразованию, срыву и уносу капель спутным потоком. Установлено, что количество срываемой с межфазной поверхности жидкости может достигать $50 \%$ и более от начального расхода жидкости в пленке. С использованием лазерной подсветки визуализирована структура течения газокапельного потока, возникающего при истечении в вакуум. Показано возникновение обратных (под углом более $90^{\circ}$ относительно оси сопла) потоков капель. Измерена температура пленки жидкости, образующаяся на внешней поверхности сопла. Показано, что пленка охлаждается до температуры, при которой давление её насыщенных паров становится равных давлению в вакуумной камере.
\end{abstract}

Ключевые слова: сопло, вакуум, пристенная пленка, смесь «вода-этанол», фазовые превращения

\section{1. Введение}

Истечение жидкостей и газожидкостных смесей в вакуум представляет, как фундаментальный, так и практический интерес. В фундаментальном плане представляют интерес исследования физических процессов и явлений, сопровождающих истечение жидкости в вакуум - мгновенное вскипание, распад на капли, фазовые переходы на поверхности и внутри капель, взаимодействие капель со сверхзвуковым газовым потоком и т.д. Для практических приложений истечение жидкости в вакуум представляет интерес, в частности, для космической техники с точки зрения загрязнения поверхностей космических аппаратов при работе дренажных устройств, двигателей управления и ориентации, систем дозаправки и т.д. Несмотря на то, что струйное истечение газа в вакуум было предметом многочисленных экспериментальных и теоретических исследований, задача совместного истечения газового потока с жидкостью, в частности с пристенной пленкой, до сих пор недостаточно изучена. Одна из особенностей рассматриваемой задачи состоит в том, что при попадании в вакуум жидкость становится мгновенно «перегретой», что приводит к её взрывообразному распаду на капли. 
В настоящее время в литературе имеются публикации по истечению воды в вакуум [1-3]. Практически все они связаны с космическими приложениями и посвящены сбросу воды с орбитальных станций через трубки разного диаметра. В этих работах показано, что при истечении в вакуум струя воды распадается на капли, которые быстро замерзают вследствие охлаждения из-за большой величины удельной теплоты испарения. В то же время мы не нашли публикаций по исследованию истечения воды в вакуум в виде пристенной пленки со спутным потоком газа.

Ранее в Институте теплофизики им. С.С. Кутателадзе СО РАН (ИТ СО РАН) были выполнены работы, посвященные решению проблемы внешнего загрязнения Международной космической станции (МКС) струями двигателей ориентации, в которых топливная пленка используется для охлаждения стенок сопла [4-5]. В качестве рабочей жидкости в этих экспериментах использовался этанол, который по основным физическим свойствам (плотность, давление насыщенных паров, удельная теплота испарения, вязкость, коэффициент поверхностного натяжения) близок к несимметричному диметилгидразину, используемому в настоящее время в качестве топлива в двигателях ориентации МКС. Было обнаружено, что при истечении в вакуум пристенная пленки жидкости, двигаясь по внутренней поверхности сопла, на выходной кромке не только распадается на капли, но также выходит на наружную поверхность сопла и начинает двигаться по ней в обратном направлении, даже против силы тяжести.

В то же время самостоятельный интерес представляет исследование влияния физических свойств жидкостей и геометрических параметров сопла не только на истечение пристенных пленок в вакуум, но и на характер их взаимодействия со спутным потоком газа внутри сопла. В данной работе в качестве сопла был выбран цилиндрический канал, а в качестве рабочих жидкостей - этанол, вода и их смесь (с объемной концентрацией 50\%). Хотя к настоящему времени опубликовано большое количество работ по взаимодействию кольцевых пристенных пленок жидкостей со спутным потоком газа, все они выполнены при относительно низких скоростях спутного газового потока, порядка 10 м/с. В экспериментах данной работы скорость спутного газового потока достигала $300 \mathrm{~m} / \mathrm{c}$.

Результаты проведенных исследований и их анализ представлены в двух частях - взаимодействие пристенных пленок этанола, воды и смеси вода-этанол со спутным потоком воздуха внутри цилиндрического канала и истечение пристенных пленок этанола, воды и их смеси их цилиндрического канала в вакуум.

\section{2. Экспериментальная установка и методы диагностики}

В основу методологии проведения экспериментальных исследований положено использование современных методов измерения и обработки данных по толщинам и скоростям пристенных пленок жидкости в каналах, по температурам пленок жидкости на внешней поверхности канала, видеосъемки с высоким пространственным и временным разрешением процесса истечения пристенной пленки жидкости со спутным потоком газа из каналов в вакуум с использованием обычной и лазерной подсветки. Работы проводились на крупномасштабной вакуумной газодинамической установке ВИКИНГ ИТ СО РАН [6], позволяющей за счет большого объема вакуумной камеры $\left(150 \mathrm{~m}^{3}\right)$ проводить исследования в импульсных режимах с большими расходами жидкости и газа, недостижимыми при работе в непрерывном режиме.

Для исследования течения пленок этанола, воды и их смесей внутри канала, а именно измерения толщины и скорости пленки, в данной работе была выбрана методика с использованием датчиков емкостного типа [7]. Данный метод не вносит возмущений в измеряемый поток, обладает хорошим временным разрешением (частота измерений 1 кГц по каждому датчику), пространственной локализацией (диаметр электрода - 1.6 мм) и хорошей точностью. Схема рабочего участка приведена на рис. 1. 


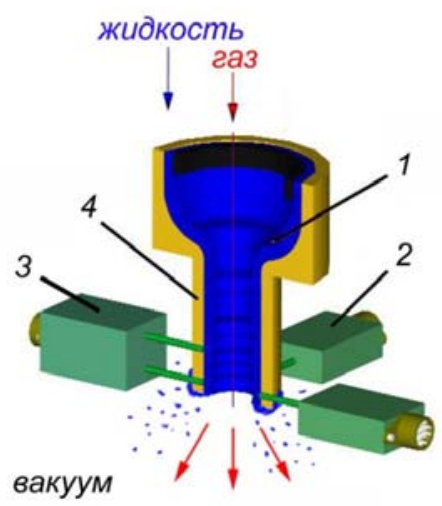

Рис. 1. Схема рабочего участка. 1 - пленка жидкости, 2 - датчик для измерения толщины, 3 - датчики для измерения толщины и скорости, 4 - канал

Для измерения скорости движения пристенной пленки использовались два последовательно расположенных зонда 3 , для измерения толщины - четыре зонда 2 , расположенных через $90^{\circ}$. Измерения толщины и скорости пристенной пленки жидкости проводились вблизи выходного сечения осесимметричного канала, в качестве которого была выбрана цилиндрическая латунная трубка внутренним диаметром 10 мм и длиной 20 мм, имеющая форкамеру диаметром 20 мм. В качестве рабочего газа использовался воздух, в качестве рабочей жидкости - этанол, вода, и их смеси с объемной концентрацией $50 \%$. Начальные температуры газа и жидкости были комнатными. Длительность импульса в экспериментах составляла, как правило, 5 секунд, при этом давление в вакуумной камере за время запуска поднималось на величину, не превышающую 0.1 Па. Рабочий участок устанавливался внутри вакуумной камеры вертикально, выходным сечением канала вниз. Массовый расход газа вирировался от 0.4 до 20 г/с, расход жидкости - от 0.3 до 2 г/с.

При проведении экспериментальных исследований важным является вопрос достоверности результатов измерений, поэтому в работе большое внимание было уделено тарировке емкостных датчиков. Обычно тарировка таких датчиков проводится в стационарных условиях, когда над поверхностью зонда создается пленка определенной толщины (которую можно измерить, например, контактным способом). Такой способ тарировки не подходит для криволинейных поверхностей, в частности, цилиндрического канала. Поэтому была реализована схема (рис. 2) с использованием втулок из диэлектрика, которые плотно вставлялись в канал и имели проточку заданной глубины над датчиком, заполняемую жидкостью.

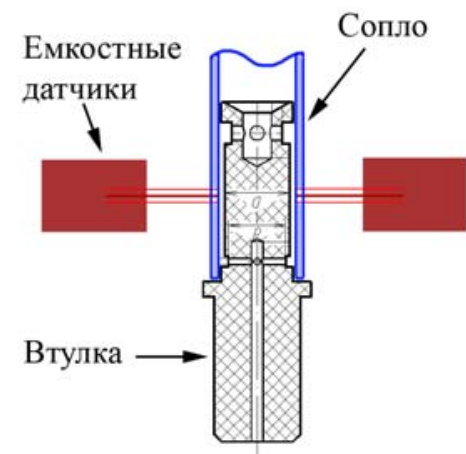

Рис. 2. Схема тарировки емкостных датчиков

Этот способ позволил получить тарировочные кривые для каждого датчика с учетом его индивидуальной чувствительности и фактической заделки датчиков относительно поверхности канала. 
Другим важным вопросом при проведении исследований в рассматриваемых условиях является измерение температуры жидкости, в частности на внешней поверхности канала после выхода пленки на срез канала и её разворота на кромке спутным газовым потоком. Обычно от датчика температуры требуется высокая точность и малое время реакции, и зачастую выбор делается в пользу термопар и термометров сопротивления. Однако при проведении исследований на крупномасштабных установках важным вопросом является борьба с шумами и наводками, обусловленными работой мощного оборудования, в частности насосной станции вакуумной камеры, и большой длиной подводящих проводов. Уровень шумов при измерениях может превышать величину полезного сигнала, в результате чего может потребоваться использование фильтров, предусилителей и АЦП, размещаемых непосредственно в вакуумной камере вблизи рабочего участка. Ввиду сложности подобных измерений в данной работе выбор был сделан в пользу малогабаритного (размером $2.8 \times 1.2 \times 1$ мм) малоинерционного полупроводникового датчика температуры Texas Instruments LM50, который закреплялся на внешней поверхности сопла вблизи среза. Данный датчик имеет высокую чувствительность, заводскую калибровку и встроенный предусилитель. Главным недостатком такого датчика является его инерционность (порядка 1 с), однако в условиях проведенных экспериментов это оказалось непринципиальным.

Сделаем несколько замечаний, касающихся свойств рабочих жидкостей и их особенностей. В таблице 1 приведены физические свойства этанола, воды и их смесей.

\section{Таблииа 1}

Физические свойства рабочих жидкостей

\begin{tabular}{|l|c|c|c|c|}
\hline \multicolumn{1}{|c|}{ Параметр } & $\begin{array}{c}\text { Ед. } \\
\text { измерения }\end{array}$ & Этанол & Вода & $\begin{array}{c}\text { Вода- } \\
\text { этанол } \\
50 \%\end{array}$ \\
\hline Давление насыщенных паров при $20^{\circ} \mathrm{C}$ & кПа & 5.86 & 2.31 & 2.95 \\
\hline Динамическая вязкость при $20^{\circ} \mathrm{C}$ & Па·с, $10^{-3}$ & 1.2 & 1.002 & 2.77 \\
\hline Плотность при $20^{\circ} \mathrm{C}$ & ${\text { кг } / \mathrm{m}^{3}, 10^{3}}{ }^{\circ}$ & 0.79 & 1 & 0.927 \\
\hline Поверхностное натяжение при $20^{\circ} \mathrm{C}$ & $\mathrm{H} / \mathrm{m}, 10^{-3}$ & 22.8 & 72.8 & 36,5 \\
\hline Температура замерзания при $101 \mathrm{\kappa Па}$ & ${ }^{\circ} \mathrm{C}$ & -114.5 & 0 & -32.5 \\
\hline Температура кипения при 101 кПа & ${ }^{\circ} \mathrm{C}$ & 78.3 & 100 & 83 \\
\hline Теплота испарения при 101 кПа & кДж/кг & 840 & 2256 & 1859 \\
\hline
\end{tabular}

Можно видеть, что давление насыщенных паров жидкостей на несколько порядков превышает рабочее давление в вакуумной камере, поэтому при попадании в вакуум жидкости становятся «мгновенно перегретыми». Кроме того, видно, что вода по сравнению с этанолом имеет существенно более высокий коэффициент поверхностного натяжения (что важно при течении тонких пленок внутри канала) и удельную теплоту фазового перехода (что важно при истечении жидкости из канала в вакуум). Но наиболее интересным является факт, что вязкость смесей «вода-этанол» может в несколько раз превышать вязкость чистых компонентов. На рис. 3 приведены зависимости вязкости смесей от концентрации при разных температурах, построенные по справочным данным [8].

Можно видеть, что существует сильная зависимость вязкости от концентрации смеси и при уменьшении температуры зависимость увеличивается. Это означает, что при течении пристенной пленки смеси «вода-этанол» даже при небольшом изменении температуры стенки канала может сильно поменяться режим течения этой пленки (число Рейнольдса пленки). Поскольку при истечении в вакуум «перегретых» жидкостей наблюдается интенсивное испарение, это приводит к сильному охлаждению жидкости на внешней поверхности сопла. 


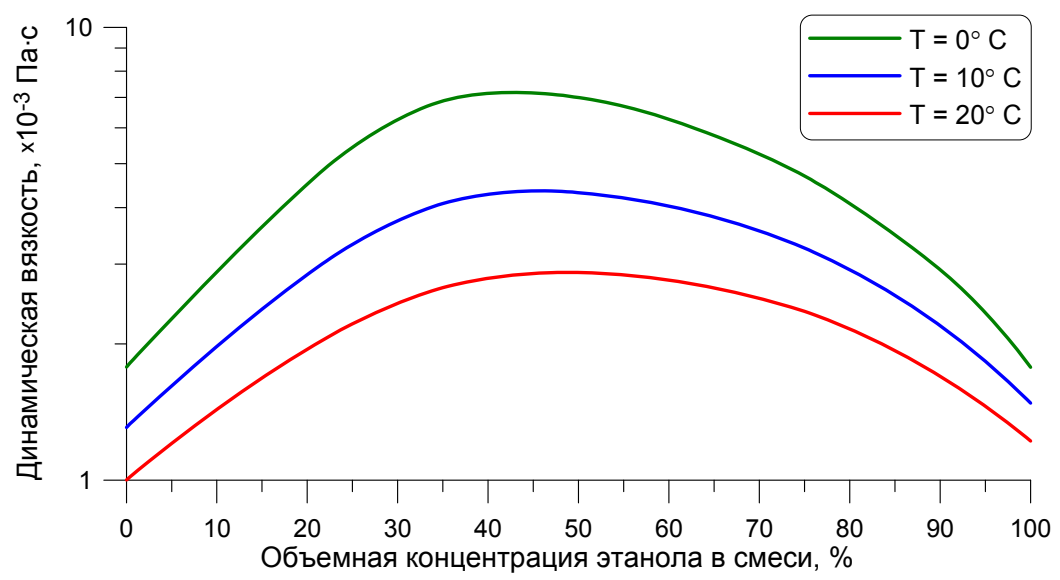

Рис. 3. Вязкость смеси «вода-этанол»

Влияние охлаждения пленки на внешней поверхности канала на течение пленки внутри канала также являлось одним из предметов исследования и будет представлено во второй части статьи.

\section{3. Результаты исследований и их анализ}

Прежде всего, сделаем несколько замечаний методологического характера. Из общих соображений ясно, что для заданного рабочего участка и рабочих жидкостей взаимодействие спутного газового потока с пристенной пленки жидкости внутри канала определяется параметрами спутного газового потока и пристенной пленки жидкости. В качестве соответствующих критериев подобия могут быть выбраны числа Рейнольдса Regas, Beбера We и Маха M спутного газового потока и число Рейнольдса $\mathrm{Re}_{\mathrm{liq}}$ пристенной пленки жидкости. При последующем истечении пристенной пленки жидкости со спутным газовым потоком в окружающее пространство определяющими будут параметры газа и пленки в выходном сечении канала и давление в окружающем пространстве (в нашем случае - в вакуумной камере). Можно также допустить, что при достижении числа Маха $\mathrm{M=1}$ в выходном сечении канала характер взаимодействия спутного газового потока с пристенной пленкой жидкости внутри канала не будет зависеть от условий в окружающем пространстве, и будет определяться только величинами выбранных критериев подобия для газа и пленки. Конечно, данное допущение справедливо только в условиях отсутствия влияния процессов тепломассообмена на внешней поверхности трубки на параметры пленки внутри канала. именно

Выбранные критерии подобия для спутного газового потока связаны между собой, а

$$
\mathrm{We}=\mathrm{Ca} \cdot \mathrm{Re}_{\mathrm{gas}}=\frac{\eta \cdot V}{\sigma} \cdot \frac{\rho \cdot V \cdot L}{\eta}=\frac{\rho \cdot V^{2} \cdot L}{\sigma}
$$

где $\mathrm{Ca}$ - число капиллярности, характеризующее соотношение между вязким трением и поверхностным натяжением; $\eta$ - динамическая вязкость газа; $\sigma$ - коэффициент поверхностного натяжения жидкости; $\rho$ - плотность газа; $V$ - скорость газа; $L$ - характерный размер, и хотя для характеристики газового потока было бы достаточно только числа Рейнольдса, в число определяющих был введен также критерий Вебера, характеризующий соотношение сил динамического напора (давления) и поверхностного натяжения. При относительно небольших скоростях спутного газового потока $(<10$ м/с) числа Вебера $\mathrm{We}<1$, и спутный поток не оказывает сильного динамического воздействия на пристенную пленку жидкости, приводя лишь к потере устойчивости и переходу к волновым режимам течения пленок. Однако при увеличении скорости спутного газового потока (до $300 \mathrm{~m} / \mathrm{c}$, как в экспериментах данной работы) он начинает оказывать сильное динамическое воздействие на пристенную 
пленку жидкости, приводя к интенсивному волнообразованию, срыву капель с межфазной поверхности и их уносу спутным потоком. При этом числа Вебера увеличиваются на порядки величины, и количество уносимой жидкости может составлять $50 \%$ и более от её начального расхода. При вычислении числа Рейнольдса $\mathrm{Re}_{\text {gas }}$ в качестве характерного размера был выбран диаметр канала, числа Рейнольдса пленки Re liq и числа Beбера We - толщина пленки:

$$
\operatorname{Re}_{\text {gas }}=\frac{\rho \cdot V \cdot d}{\eta}, \quad \operatorname{Re}_{\text {liq }}=\frac{\rho_{\text {liq }} \cdot V_{\text {liq }} \cdot \delta}{\eta_{\text {liq }}}=\frac{G_{\text {liq }}}{\eta_{\text {liq }} \cdot \pi \cdot d}, \quad \mathrm{We}=\frac{\rho \cdot V^{2} \cdot \delta}{\sigma},
$$

где $d$ - диаметр канала; $\rho_{\text {liq }}, \eta_{\text {liq }}, G_{\text {liq }}$ - плотность, вязкость, расход жидкости; $V_{\text {liq }}, \delta$ - скорость и толщина пленки, соответственно. В экспериментах число Рейнольдса газа изменялись в диапазонах от $3 \times 10^{3}$ до $1.6 \times 10^{5}$, пленки - от 8 до 50, число Вебера - от 3 до 50, число Маха - от 0.02 до 1.

Как отмечалось, в качестве основного метода диагностики пристенных пленок жидкости внутри канала использовались датчики емкостного типа, что позволило исследовать волновые характеристики пленок, а также получить данные по их локальным параметрам толщине и скорости. Сначала рассмотрим влияние определяющих параметров (чисел $\mathrm{Re}_{\mathrm{gas}}$ и $\mathrm{Re}_{\mathrm{liq}}$ ) на характер течения пленок этанола, а далее приведем основные отличия в характере течения пленок воды и смеси «вода-этанол». На рис. 4 в качестве примера представлены зависимости толщины пленки этанола за время запуска, измеренной четырьмя датчиками.
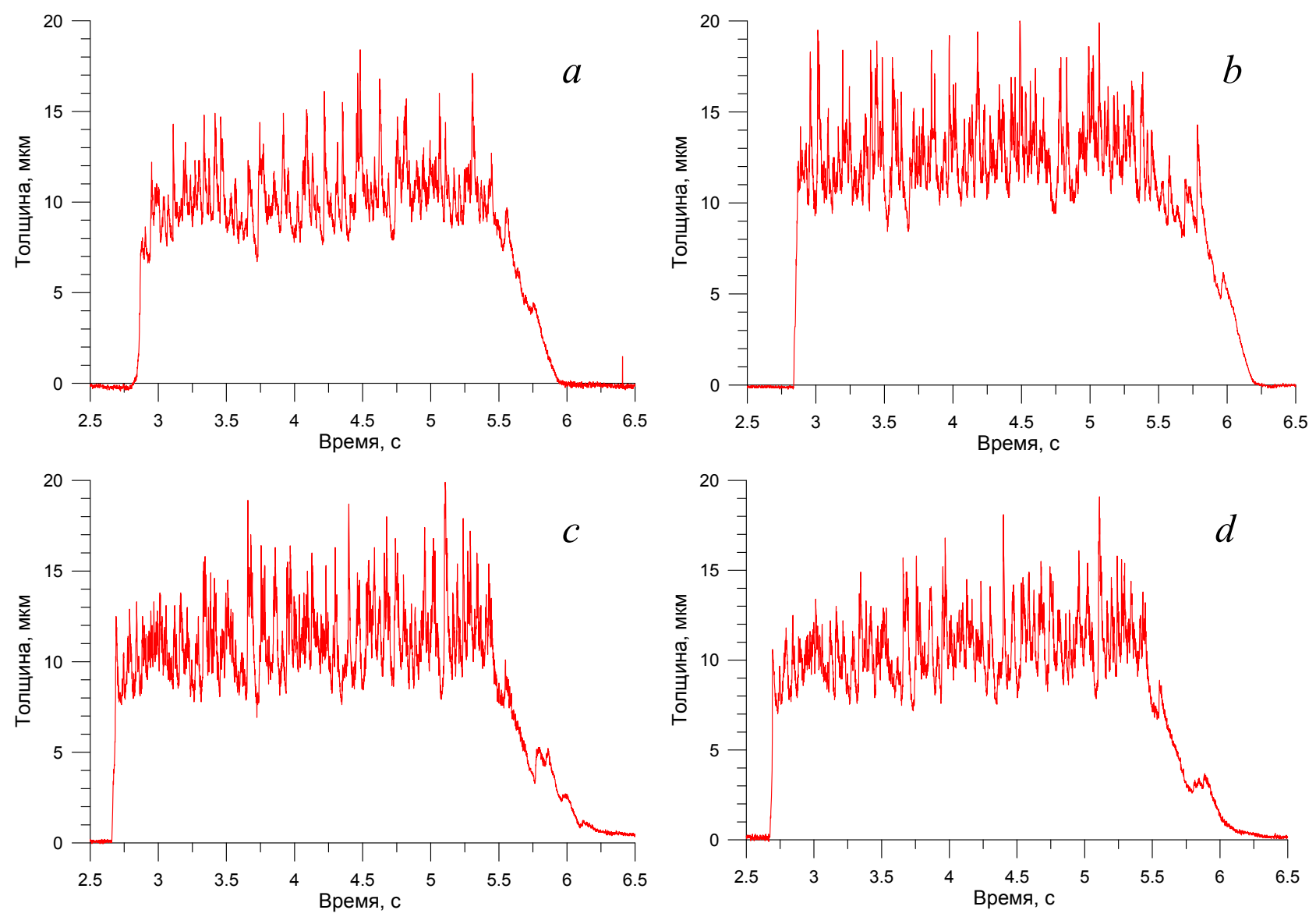

Рис. 4. Временные зависимости толщины пристенной пленки этанола по показаниям четырех датчиков. $a, b, c, d$ - датчики $1,2,3,4$, соответственно. $\operatorname{Re}_{\text {gas }}=7.7 \times 10^{4}, \operatorname{Re}_{\text {liq }}=8.8$

Видно, что все четыре датчика показывают весьма близкие значения, что свидетельствует об относительно равномерном распределении жидкости по внутренней поверхности 
канала. Видно также, что для данного режима течения толщины пленки в выходном сечении канала составляет около 10 мкм, то есть пленка тонкая. На рис. 5 также для примера приведены показания двух последовательно расположенных датчиков для другого режима течения. На рис. 6 эти же данные (рис. 5) «растянуты» во времени. Из представленных данных отчетливо виден момент прихода пленки жидкости на «верхний», а затем на «нижний» датчики. Далее регистрируется изменение мгновенной (частота опроса датчиков составляла 1 кГц) толщины пленки, после чего происходит спад и толщина пленки уменьшается практически до нуля. При детальном рассмотрении видно, что пленка имеет четко выраженную волновую структуру с относительно большой частотой (временной масштаб $\approx 40$ мс, частота $\approx 25$ Гц) и амплитудой волн, сравнимой с её толщиной. Видно также, что волны имеют крутой фронт, а затем идет пологая часть, по поверхности которой движутся более мелкие волны (рябь).

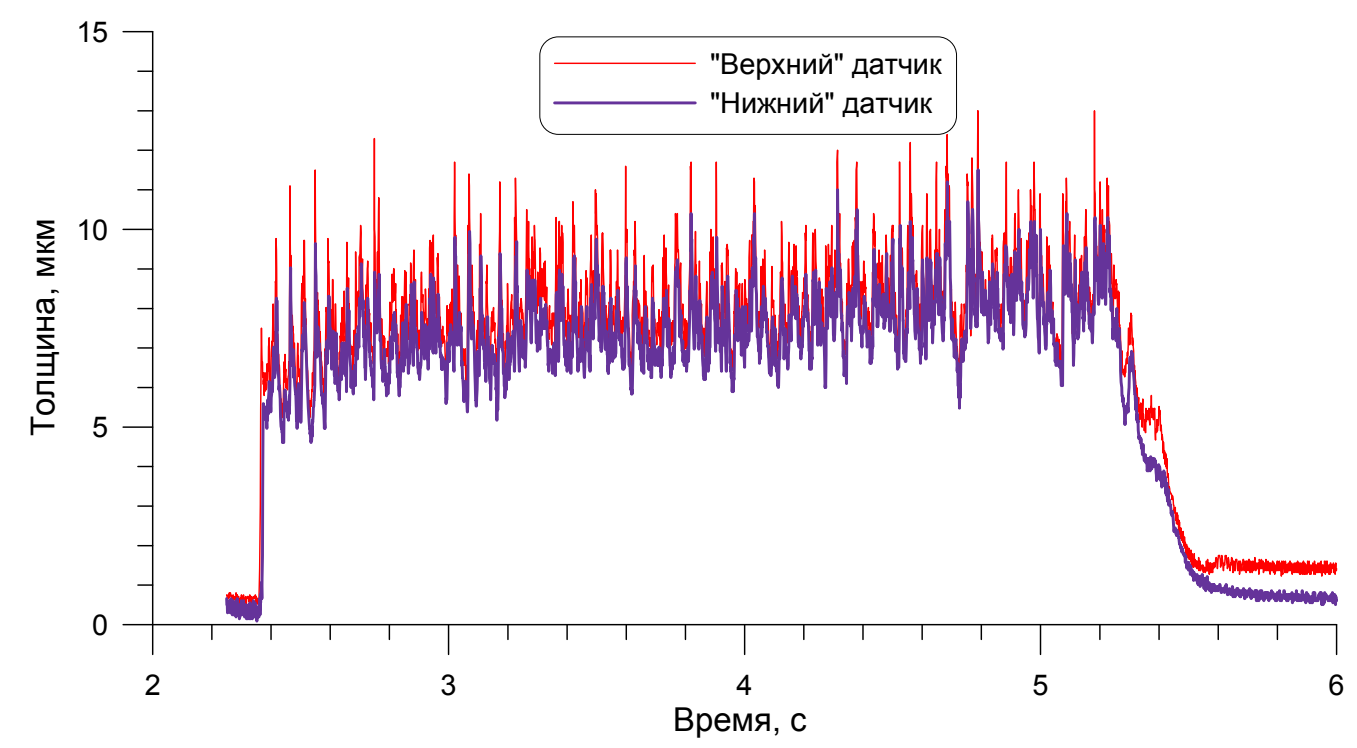

Рис. 5. Толщина пленки этанола. $\mathrm{Re}_{\mathrm{gas}}=1.3 \times 10^{5}, \mathrm{Re}_{\mathrm{liq}}=8.8$

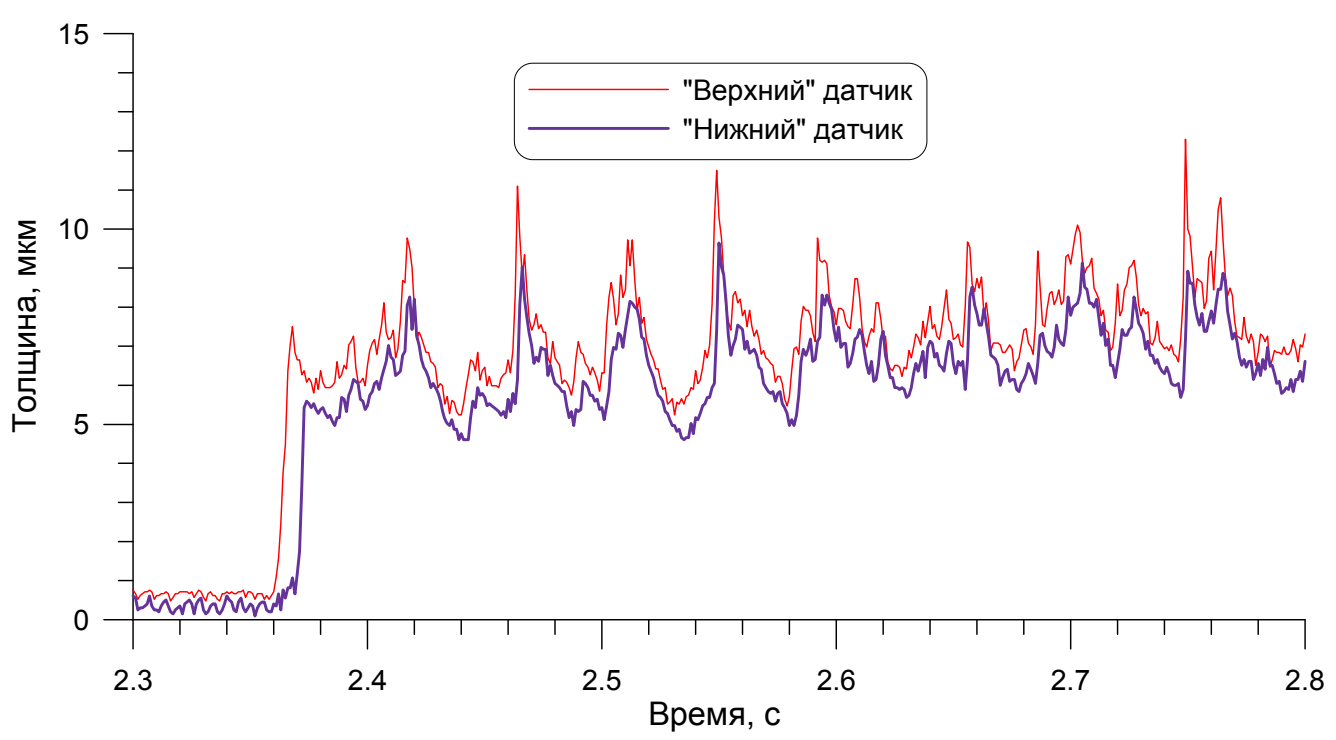

Рис. 6. Толщина пленки этанола, «растянутая» по времени. $\operatorname{Re}_{\mathrm{gas}}=1.3 \times 10^{5}, \mathrm{Re}_{\mathrm{liq}}=8.8$ 
Проведенные эксперименты позволили получить количественные данные по средним толщинам пленок этанола в рассматриваемых условиях, а именно при изменении скорости спутного газового потока от 6 до 317 м/с (при изменении числа Маха от 0.02 до 1) и провести их обобщение. Соответствующие результаты приведены на рис. 7, из которого видно, что в исследованном диапазоне режимных параметров средние толщины пленок удовлетворительно обобщаются по числу Рейнольдса $\mathrm{Re}_{\mathrm{gas}}$ спутного газового потока.

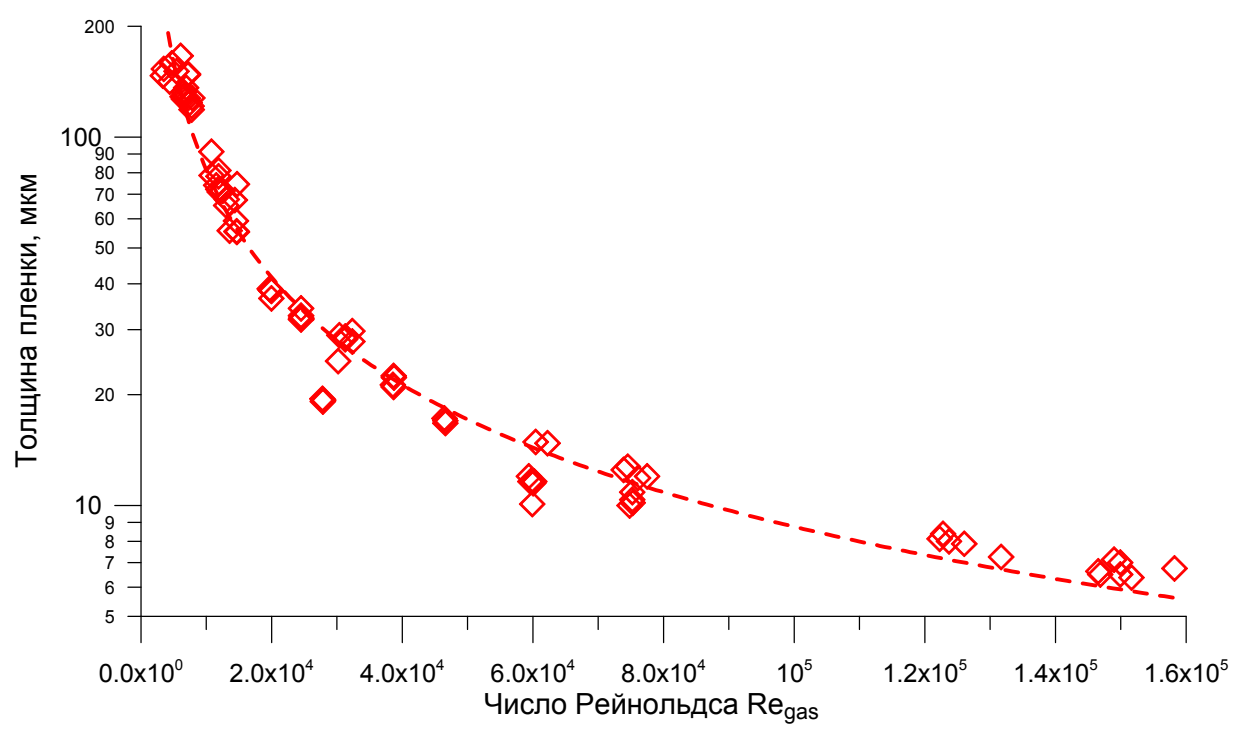

Рис. 7. Зависимость толщина пленки этанола от $\mathrm{Re}_{\mathrm{gas}}$. $\mathrm{Re}_{\mathrm{liq}}=8.8$

Дополнительным подтверждением сказанному являются экспериментальные данные, приведенные на рис. 8 для двух режимов истечения, отличающихся скоростью спутного газового потока $V\left(60\right.$ м/с и 106 м/с), но при одинаковых числах Рейнольдса $\operatorname{Re}_{\text {gas }}=4.3 \times 10^{4}$, что обеспечивалось соответствующим изменением плотности газового потока. Можно видеть, что при некотором отличии волновых характеристик пленок в этих режимах, средние толщины пленок одинаковы, что говорит об определяющем влиянии числа Рейнольдса спутного потока газа на параметры пленки.

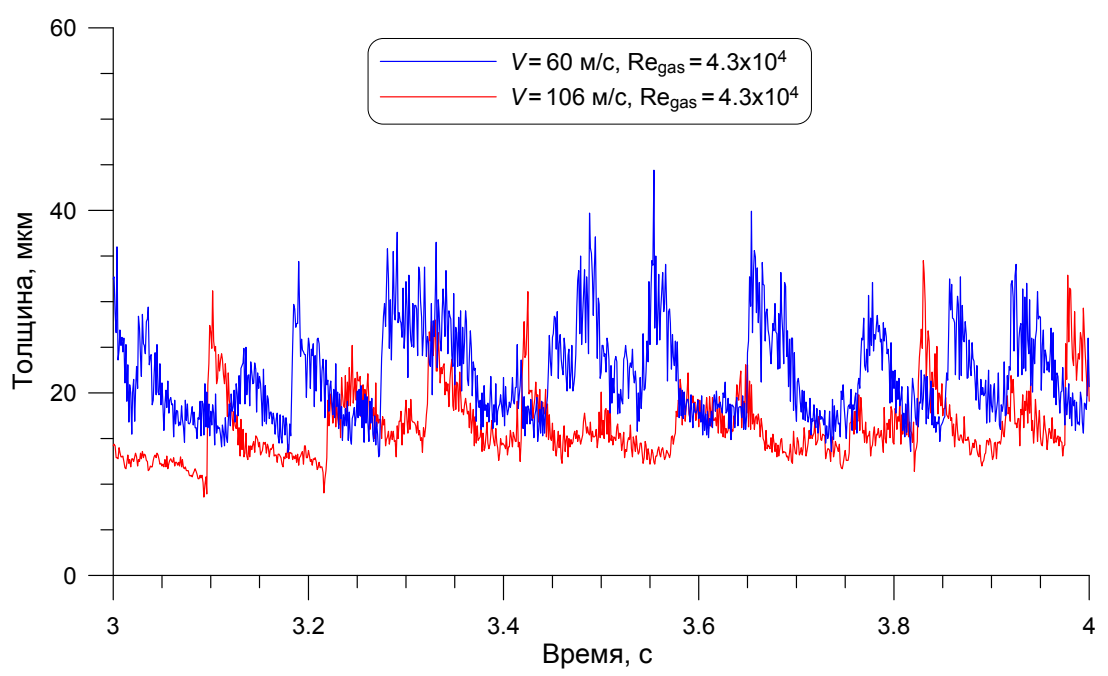

Рис. 8. Толщина пленки этанола. $\mathrm{Re}_{\mathrm{liq}}=8.8$

Проведенные измерения по двум последовательно расположенным датчикам позволили также получить экспериментальные данные по скоростям переднего фронта движения пристенных пленок и скоростям волн на межфазной поверхности. Соответствующие ре- 
зультаты для этанола приведены на рис. 9 в зависимости от числа Рейнольдса Regas. Хотя наблюдается некоторый разброс экспериментальных данных, в целом они также коррелируют с числом Рейнольдса Regas .

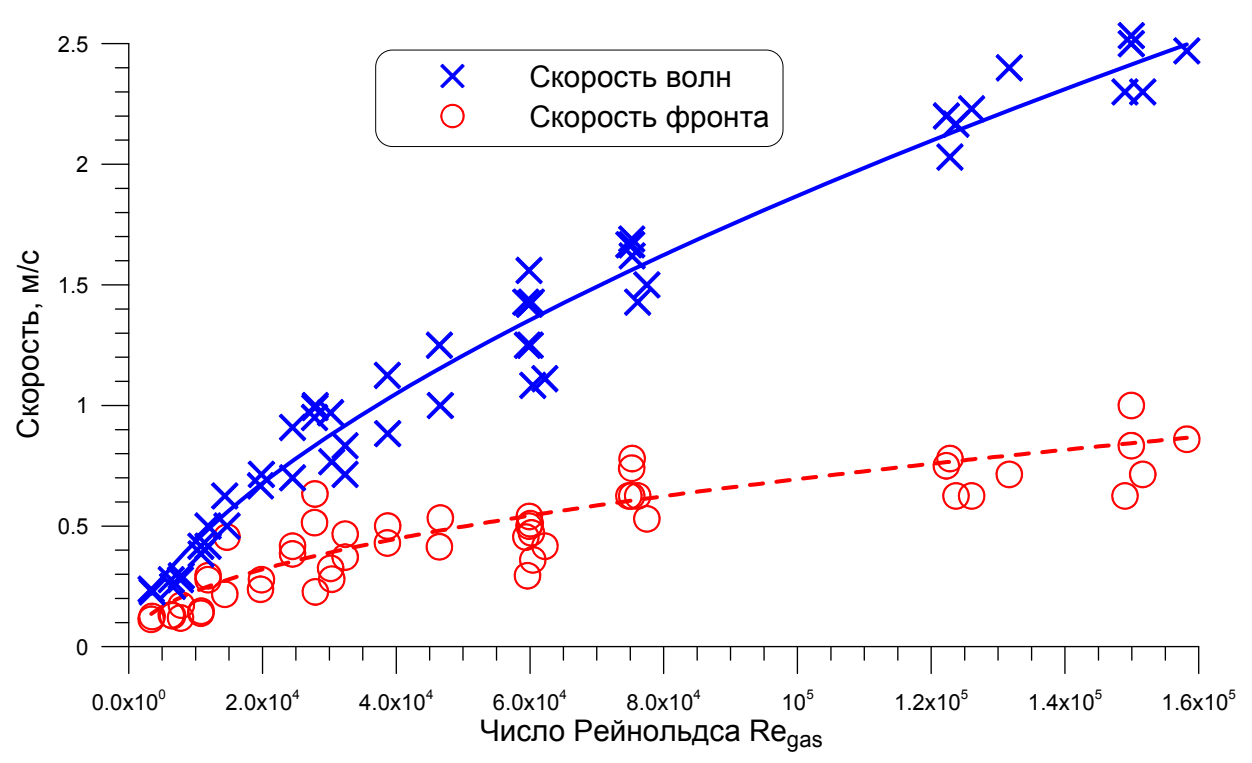

Рис. 9. Скорость пленки этанола. $\mathrm{Re}_{\mathrm{liq}}=8.8$

Полученные экспериментальные данные по средним толщинам и скоростям пристенных пленок жидкости вблизи выходного сечения канала позволили определить расход жидкости на выходе из канала. При известном начальном расходе жидкости это позволило оценить количество жидкости, срываемой с поверхности пленки и уносимой спутным газовым потоком (рис. 10). Оказалось, что это количество может достигать более $50 \%$ от начального расхода этанола и коррелирует с числом Вебера We, максимальное значение которого составляло $\mathrm{We}=50$. По имеющимся представлениям такие числа Вебера соответствуют режимам сильного динамического воздействия как на пристенные пленки, так и на капли в потоке.

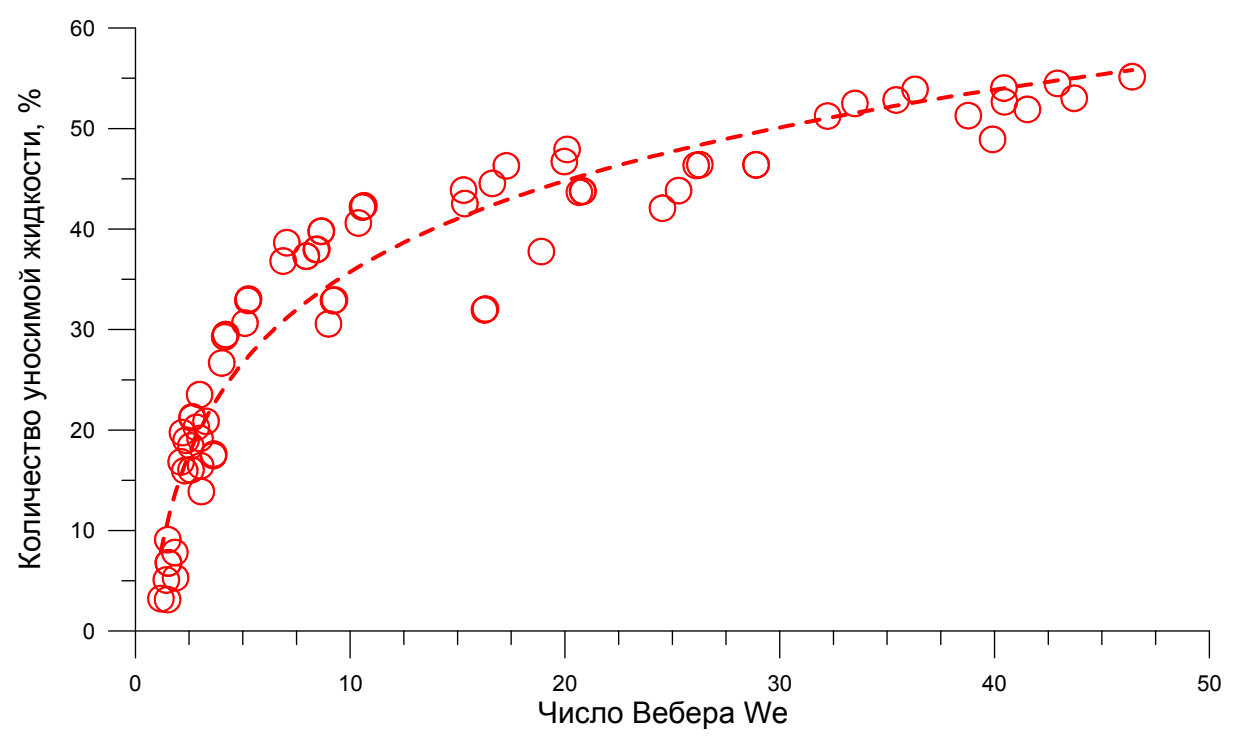

Рис. 10. Зависимость количества уносимой жидкости от числа Вебера

Столь значительный унос жидкости с межфазной поверхности и высокие числа Вебера связаны, по-видимому, с физическими свойствами этанола (в частности, малым коэффи- 
циентом поверхностного натяжения). Другими физическими свойствами жидкостей, важными для рассматриваемой задачи, являются вязкость, давление насыщенных паров и удельная теплота испарения. Для установления их влияния на характер взаимодействия спутного газового потока с пристенной пленкой жидкости и при истечении в вакуум в экспериментах наряду с этанолом в качестве рабочих жидкостей использовались также вода и $50 \%$ смесь воды и этанола. У воды коэффициент поверхностного натяжения более чем в 3 раза превышает коэффициент поверхностного натяжения этанола, что может быть определяющим для формирования тонких, толщиной порядка 100 мкм пленок. Подтверждением сказанному являются экспериментальные данные по толщинам пленки воды, представленные на рис. 11 по показаниям четырех датчиков. Хотя система подачи воды для организации пристенной пленки была та же самая, что и для этанола, а секундный расход воды (число $\mathrm{Re}_{\text {liq }}$ ) был даже больше, чем для этанола, поведение пристенной пленки воды отличается от этанола. Видно, что в отличие от этанола (см. рис. 4) пленка воды не распределяется равномерно по внутренней поверхности канала. Кроме того, можно видеть образование сухих пятен на поверхности канала и возникновение отдельных ручейков - ривулетов.
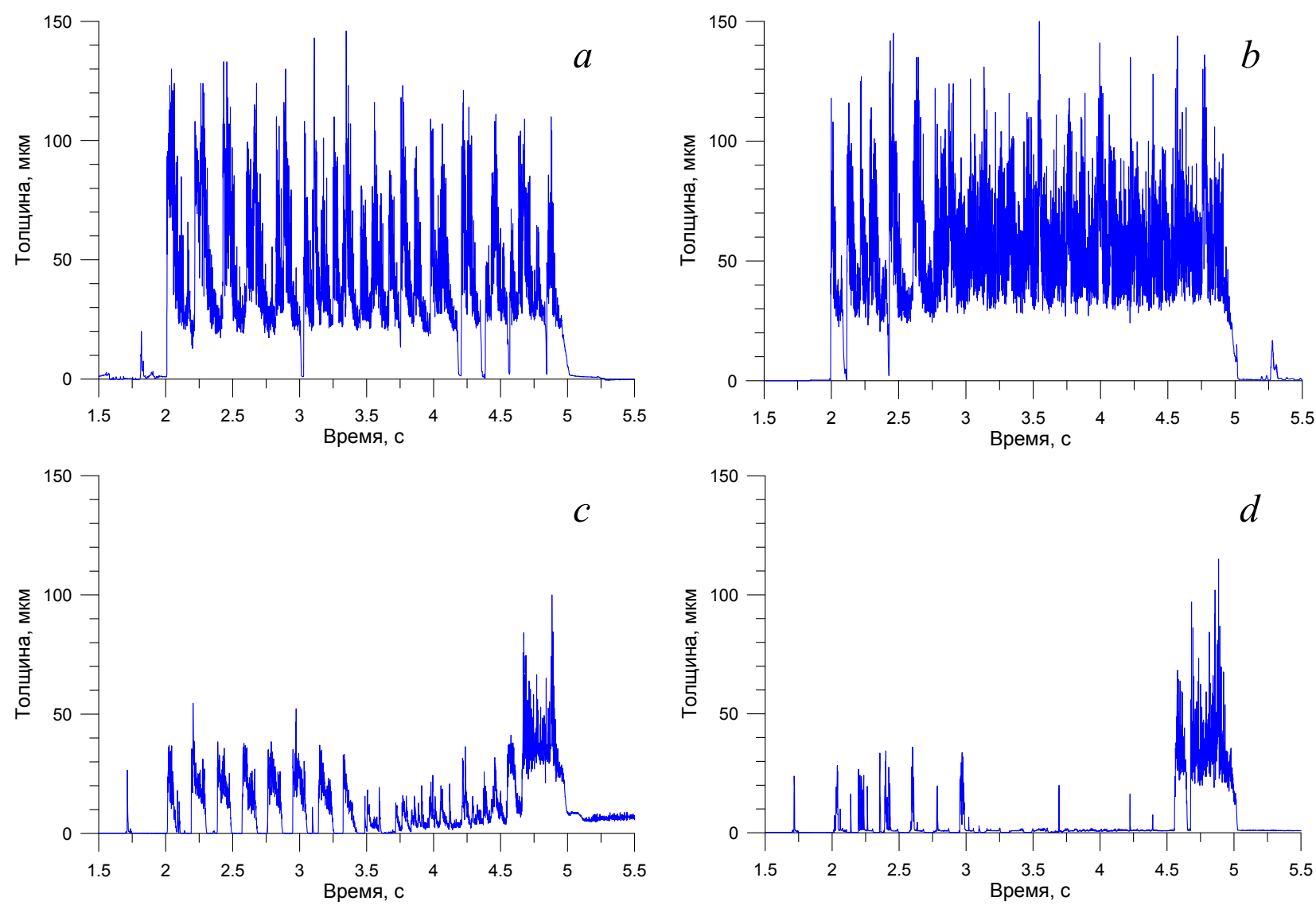

Рис. 11. Временные зависимости толщины пристенной пленки воды по показаниям четырех датчиков. $a, b, c, d$ - датчики $1,2,3,4$, соответственно. $\mathrm{Re}_{\mathrm{gas}}=4 \times 10^{4}, \mathrm{Re}_{\mathrm{liq}}=49$

Более детально это можно видеть также на рис. 12 и 13, на которых представлены «растянутые» данные по толщинам пленок воды для других режимов течения.

Можно также отметить, что при ривулетных режимах течения средние толщины пленок воды из-за меньшей площади омываемой поверхности становятся больше по сравнению с кольцевым режимом течения пленок (при прочих равных условиях). Для пленок воды в условиях проведенных экспериментов наблюдается увеличение амплитуды волн. 


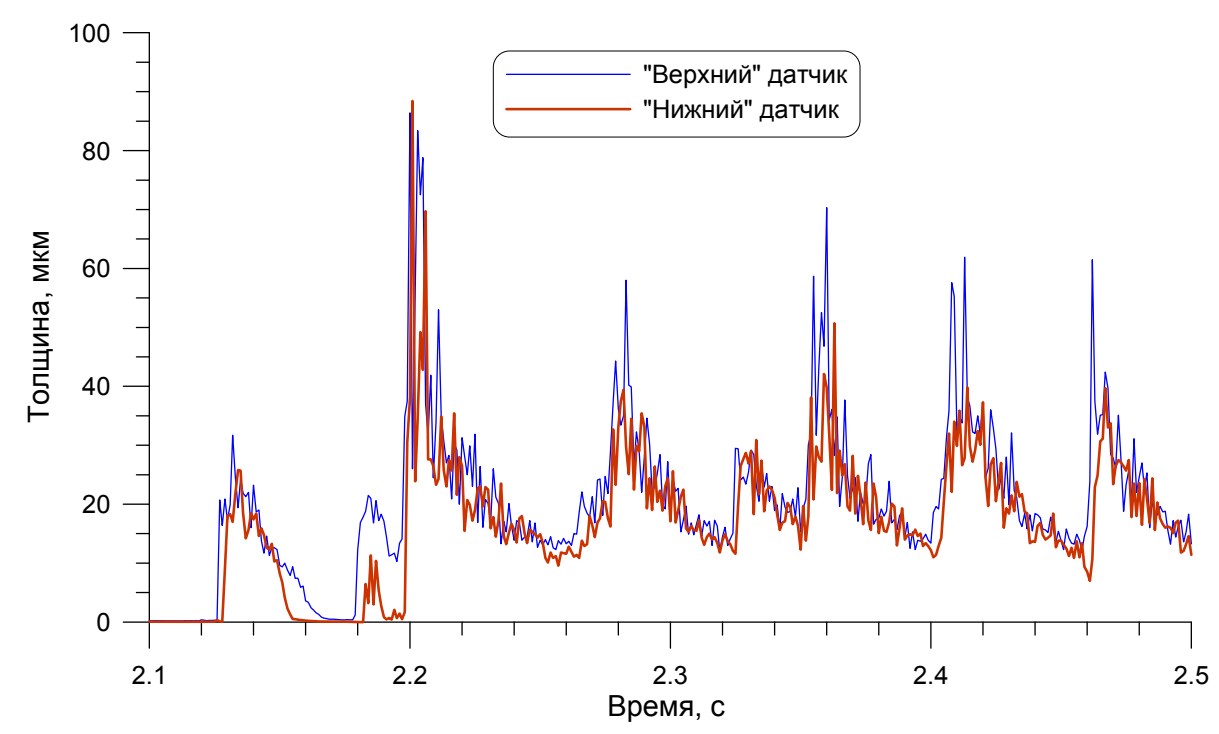

Рис. 12. Толщина пленки воды. $\mathrm{Re}_{\mathrm{gas}}=3.1 \times 10^{4}, \mathrm{Re}_{\mathrm{liq}}=44$

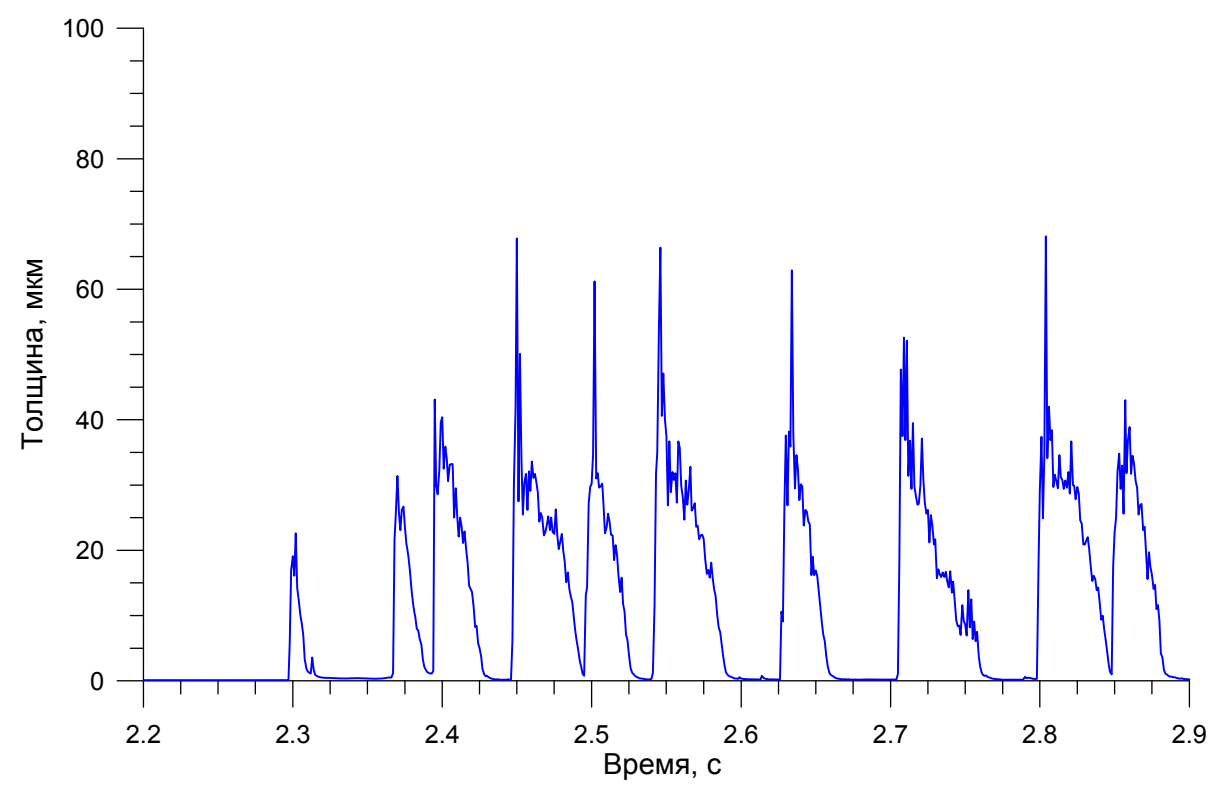

Рис. 13. Толщина пленки воды. $\mathrm{Re}_{\mathrm{gas}}=4.8 \times 10^{4}, \mathrm{Re}_{\mathrm{liq}}=44$

Перейдем теперь к анализу полученных результатов по течениям пленок смеси «водаэтанол». Такие смеси в виде пленок могут использоваться, например, для охлаждения теплонапряженных конструктивных элементов в микроэлектронике. В экспериментах данной работы выбрана смесь «вода-этанол» с объемной концентрацией $50 \%$, при которой влияние концентрации на физические свойства смеси (вязкость) наибольшее. На рис. 14, как и ранее для пленок этанола и воды, представлены экспериментальные данные по толщинам пленки 50 \% смеси «вода-этанол», полученные по показаниям четырех датчиков. При этом определяющие параметры течения (числа Рейнольдса $\mathrm{Re}_{\mathrm{gas}}$ и $\mathrm{Re}_{\mathrm{liq}}$ ) выбраны теми же, что и для пленки этанола (рис. 4).

Можно видеть, что результаты измерений для пленок этанола и его смеси с водой качественно близки, однако средняя толщина пленки смеси больше, чем для пленки этанола. Этот результат является ожидаемым из-за большей вязкости смеси «вода-этанол» по сравнению с этанолом. 

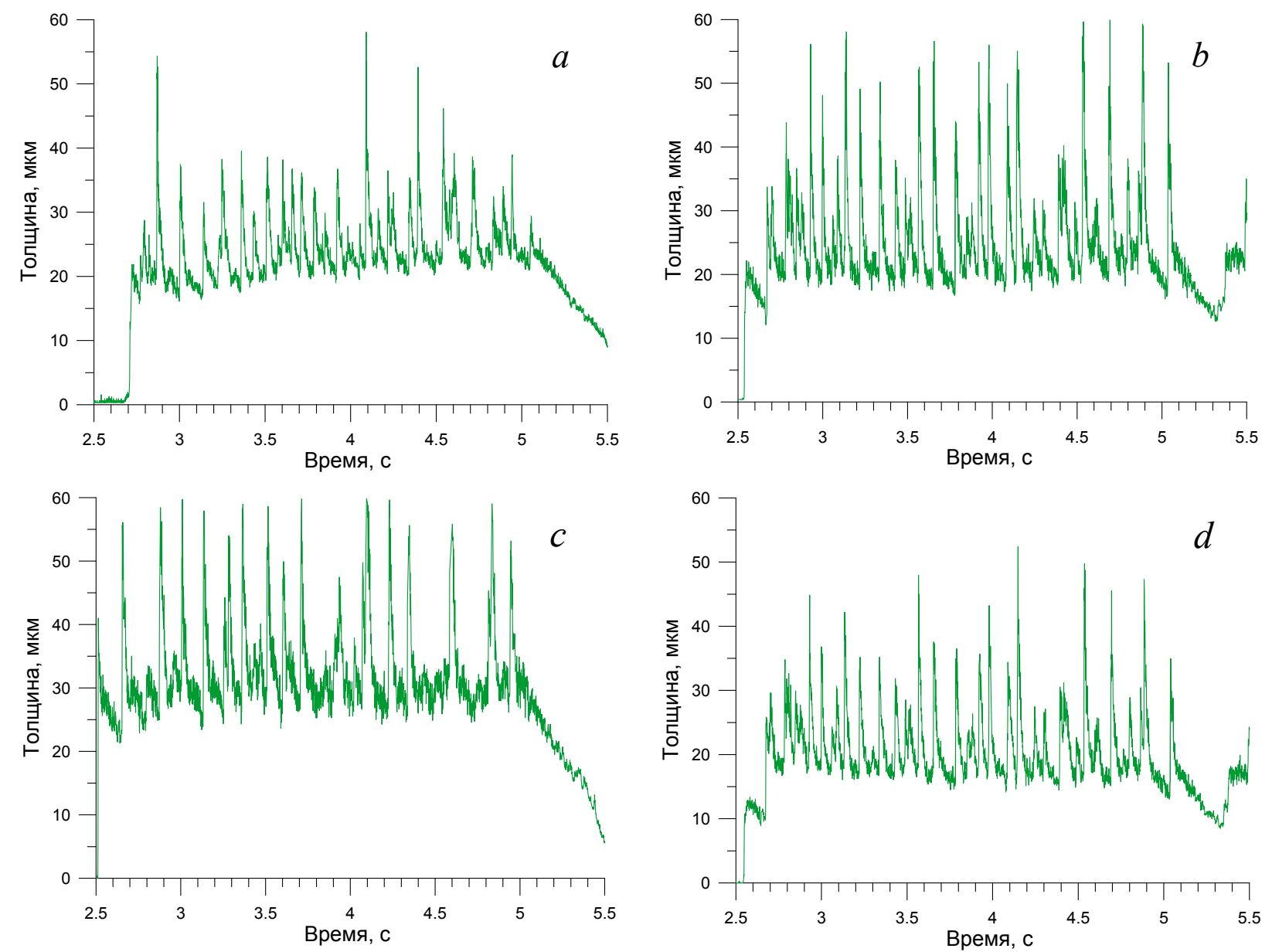

Рис. 14. Временные зависимости толщины пристенной пленки смеси «вода-этанол» по показаниям четырех датчиков. a, b, c, d - датчики $1,2,3,4$, соответственно. $\operatorname{Re}_{\text {gas }}=3.3 \times 10^{4}, \operatorname{Re}_{\text {liq }}=8.3$

На рис. 15 представлена «растянутая по времени» запись изменения «мгновенной» (частота опроса 1 кГц) толщины пленки смеси по данным двух последовательно расположенных датчиков для одного из режимов течения.

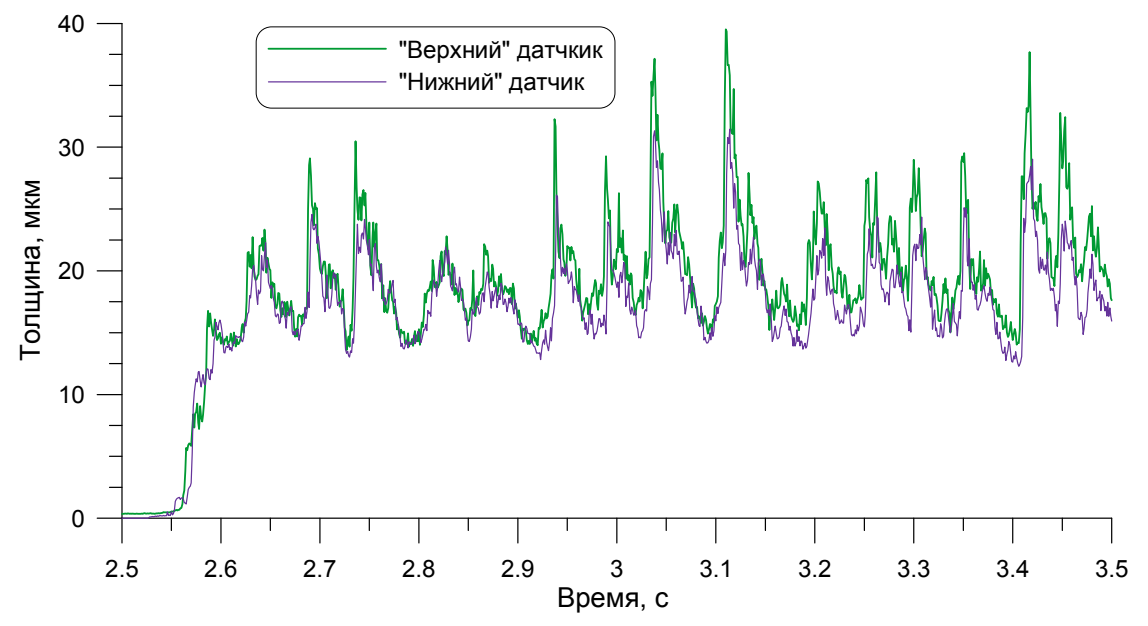

Рис. 15. Толщина пленки смеси «вода-этанол». $\mathrm{Re}_{\text {gas }}=5 \times 10^{4}, \mathrm{Re}_{\mathrm{liq}}=8.3$

Здесь также, как для этанола, можно видеть момент прихода пленки смеси на верхний по потоку и далее на нижний по потоку датчики. Видна также волновая структура пленки смеси, включающая в себя периодические волны с крутым фронтом и следующие за ними 
пологие части с более мелкой структурой. При этом, как показывают эксперименты, с увеличением числа Рейнольдса спутного газового потока частота следования волн увеличивается, а амплитуда волн и их средняя толщина уменьшаются, что можно видеть на рис. 16.
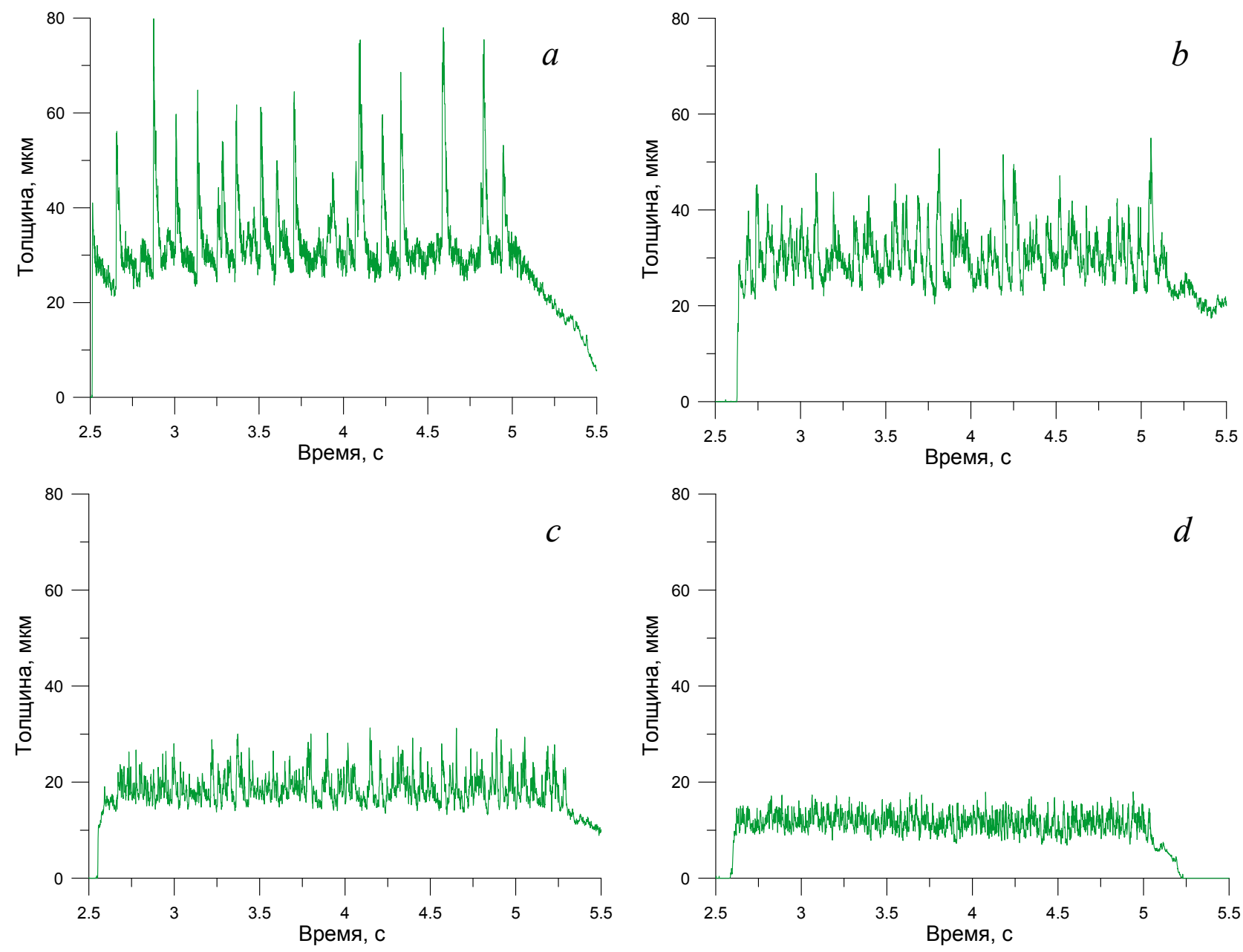

Рис. 16. Толщина пленки смеси «вода-этанол» в зависимости от числа Рейнольдса спутного газового потока. $\mathrm{Re}_{\mathrm{gas}}: a-3.3 \times 10^{4}, b-5 \times 10^{4}, c-9.9 \times 10^{4}, d-1.6 \times 10^{5} ; \mathrm{Re}_{\mathrm{liq}}=8.3$

При этом, как и ранее для этанола, средняя толщина пристенных пленок смеси «водаэтанол» в условиях проведенных экспериментов удовлетворительно обобщается по числу Рейнольдса спутного газового потока. Соответствующие данные для пленок смеси «водаэтанол» и этанола приведены на рис. 17.

\section{4. Заключение}

Выполнен цикл экспериментальных исследований по взаимодействию пристенных пленок этанола, воды и их смеси со спутным газовым потоком в цилиндрическом канале в диапазонах чисел Рейнольдса газа Regas $=3 \times 10^{3} \div 1.6 \times 10^{5}$, Рейнольдса пленки $\operatorname{Re}_{\text {liq }}=8 \div 50$, числа Маха $\mathrm{M}=0.02 \div 1$. С использованием зондов емкостного типа исследованы волновые характеристики пленок, а также измерены их локальные толщины и скорости вблизи выходного сечения канала. Показано определяющее влияние вязкости и коэффициента поверхностного натяжения на волновые характеристики пленок и их взаимодействие со спутным газовым потоком. Установлено, что для тонких (порядка 100 мкм) пристенных пленок воды, обладающей существенно большим по сравнению с этанолом и его смесям с водой коэффициентом поверхностного натяжения, характерно возникновение ривулетного режи- 
ма течения с образованием сухих пятен, в то время как для этанола и его смесей с водой наблюдается устойчивая кольцевая пленка.

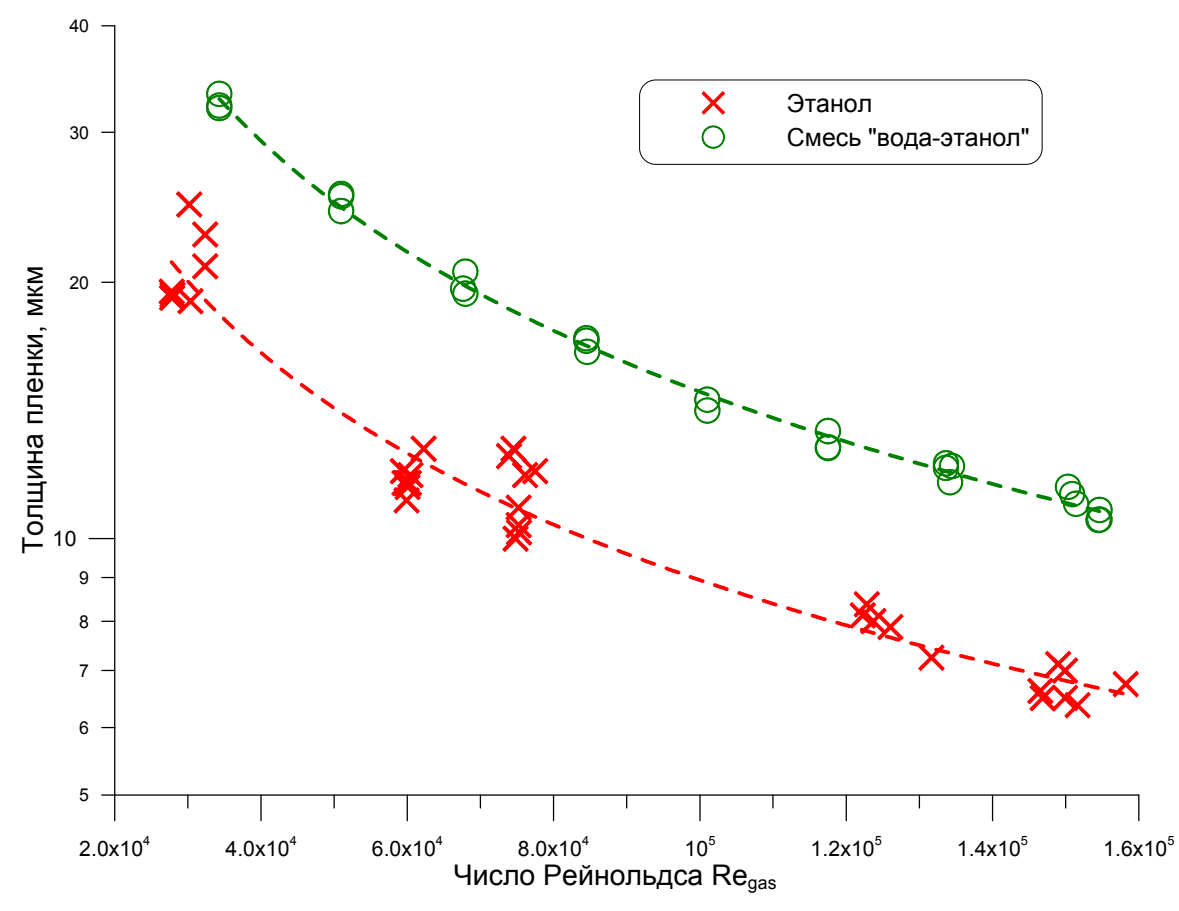

Рис. 17. Толщины пленок этанола и смеси «вода-этанол». $\operatorname{Re}_{\text {liq }}=8.3$

Установлено, что в условиях проведенных экспериментов спутный газовый поток оказывает сильное динамическое воздействие на пристенные пленки жидкости, приводя к интенсивному волнообразованию, срыву капель с межфазной поверхности и их уносу спутным потоком. При этом количество срываемой жидкости может достигать более 50\% от её начального расхода. Показано, что средние толщины пленок удовлетворительно обобщаются по числу Рейнольдса спутного газового потока, а количество срываемой жидкости коррелирует с числом Вебера.

Поскольку полученные в экспериментах данные по толщинам и скоростям пристенной пленки содержат формально информацию о касательном напряжении на межфазной границе, они могут быть использованы для тестирования разрабатываемых моделей взаимодействия высокоскоростных турбулентных потоков газа с пристенными пленками жидкостей.

\section{Благодарность}

Работа выполнена при финансовой поддержке Российского фонда фундаментальных исследований, проект РФФИ №16-38-00406.

\section{Литература}

1. Mikatarian R.R., Anderson R.G. An Experimental Investigation of a Liquid Jet Expelled into a Vacuum. // J. of Spacecraft and Rockets. 1966. Vol.3. - P. 267.

2. Fuchs H., Legge H. Flow of a Water into Vacuum//Acta Astronautica. 1979. Vol.6. - Pp.1213-1226.

3. Alred J.W., Smith L.N., Wang K.C., Lumpkin F.E., Fitzgerald S.M. Modelling of Water Injection into Vacuum // Proc. Eighth Annual Thermal and Fluids Analysis Wokshop. Spacecraft Analysis and Design. 1997. Houston, Texas. 
4. Ярыгин В.Н., Приходько В.Г., Ярыгин И.В., Герасимов Ю.И., Крылов А.Н. Газодинамические аспекты проблемы загрязнения Международной космической станции. 1. Модельные эксперименты // Теплофизика и Аэромеханика. 2003. Т.10, № 2. - С. 575-586.

5. Герасимов Ю.И., Ярыгин В.Н. Газодинамические защитные устройства для двигателей ориентации космических аппаратов и орбитальных станций. Концепция, модельные и натурные эксперименты//Физико-химическая кинетика в газовой динамике. 2016. Т. 17, вып. 4. http://chemphys.edu.ru/issues/2016-17-4/articles/671/

6. Приходько В.Г., Храмов Г.А., Ярыгин В.Н. Крупномасштабная криогенно-вакуумная установка для исследования газодинамических процессов // Приборы и техника эксперимента. 1996. № 2. - С. 162-164.

7. Серов А.Ф., Котов С.В., Назаров А.Д., Павленко А.Н., Печеркин Н.И., Чехович В.Ю. Емкостной измеритель локальной толщины пленки жидкости // Приборы и техника эксперимента. 1997. T.40, №1. - С.136-139.

8. Стабников В.Н., Ройтер И.М., Прощук Т.Б. Этиловый спирт. 1976. М.: Пищ. пром. - 272 с.

Статья поступила в редакцию 31 января 2018 г. 